\title{
PEMBUATAN BIOPELET DARI KAYU PUTIH DENGAN PENAMBAHAN GONDORUKEM SEBAGAI BAHAN BAKAR ALTERNATIF
}

\section{THE MANUFACTURE OF BIOPELLET FROM MIXTURE OF CAJEPUT AND GONDORUKEM AS ALTERNATIVE FUEL}

\author{
${ }^{1}$ Sofia Mustamu, ${ }^{2}$ Gysberth Pattiruhu, \\ ${ }^{1)}$ Jurusan Kehutanan Fakultas Pertanian Universitas Pattimura \\ ${ }^{2)}$ Jurusan Teknologi Hasil Pertanian Fakultas Pertanian Universitas Pattimura \\ Jln. Ir. M. Putuhena, Kampus Poka - Ambon, Kode Pos 97233 \\ email: sofiamustamu@yahoo.co.id
}

\begin{tabular}{|l|l}
\hline Diterima : 03 Februari 2018 & Disetujui : 10 Maret 2018 \\
\hline
\end{tabular}

\begin{abstract}
Intisari
Biopelet adalah salah satu energi alternatif terbarukan yang memiliki keseragaman ukuran, bentuk, densitas, dan kandungan energi. Tujuan penelitian ini adalah menguji karakteristik biopelet campuran kayu putih dan gondorukem, serta menentukan komposisi bahan baku yang dapat menghasilkan biopelet dengan kualitas terbaik. Komposisi campuran bahan baku kayu putih dan gondorukem adalah 95\%:5\%, 90\%:10\%, 80\%:20\%, 70\%:30\%, 60\%:40\%, 50\%:50\%, Kayu Putih murni dan Gondorukem murni. Pembuatan biopelet menggunakan serbuk 20 mesh dengan tekanan $526.4 \mathrm{~kg} / \mathrm{cm}^{2}$ pada suhu $200{ }^{\circ} \mathrm{C}$ selama 15 menit. Pengujian biopelet yang dilakukan meliputi: kadar air, kerapatan, zat terbang, kadar abu, karbon terikat, dan nilai kalor. Hasil pengujian menunjukkan biopelet yang mempunyai kualitas terbaik terdapat pada campuran Kayu Putih 70\% dan Gondorukem 30\% dengan nilai kerapatan $0,84 \mathrm{~g} / \mathrm{cm}^{3}$, kadar air 5,89\%, kadar abu 2,42\%, zat terbang 73,99\%, karbon terikat $18,96 \%$, dan nilai kalor $5152 \mathrm{kkal} / \mathrm{kg}$.
\end{abstract}

Kata Kunci : Biopelet, Limbah Kayu Putih, Limbah Gondorukem, Nilai Kalor

\begin{abstract}
Biopelet is one of the renewable energy alternatives that have uniformity of size, shape, density, and energy content. The purpose of this study was to examine the characteristics of biopelet consisting of a mixture of cajeput and gondorukem, and to determine the composition of the raw materials that can produce a biopelet with the best quality. The compositions of a mixture in this research are as follow 95\%:5\%, 90\%:10\%, 80\%:20\%, 70\%:30\%, 60\%:40\%, 50\%:50\%, cajeput 100\% and gondorukem $100 \%$. The manufacture of biopelet used a 20 mesh of dust with the pressure of $526.4 \mathrm{~kg} / \mathrm{cm}^{2}$ at a temperature of $200{ }^{\circ} \mathrm{C}$ for 15 minutes. Types of tests performed on biopelet include density, moisture content, volatile matter, ash content, carbon bonded, and calorific value. The results of the best quality of biopelet was in the percentage of cajeput and gondorukem was 70\%:30\%, tests showed densities of biopelet $0,84 \mathrm{~g} / \mathrm{cm}^{3}$, moisture content $5,89 \%$, ash content $2,42 \%$, volatile matter $73,99 \%$, fixed carbon $18,96 \%$, and calorific value $5152 \mathrm{kkal} / \mathrm{kg}$.
\end{abstract}

Keywords: biopellet, cajeput waste, caloric value, gondorukem waste

\section{PENDAHULUAN}

Menipisnya ketersediaan bahan bakar fosil dapat memberikan pengaruh terhadap kondisi sosial ekonomi masyarakat sebagai pengguna bahan bakar dan juga mengakibatkan peningkatan harga bahan bakar minyak. Untuk mengatasi masalah tersebut maka timbul suatu pemikiran untuk mencari dan mengembangkan sumber energi baru yang murah dan ramah lingkungan yang berasal dari biomassa. Biomassa dapat 
diperoleh dari sisa hasil hutan dan perkebunan, biji dan limbah pertanian, kayu dan limbah kayu, limbah hewan, tanaman air, tanaman kecil, dan limbah industri serta limbah pemukiman (Bergmen dan Zerbe, 2006). Sumber biomassa yang berasal dari limbah salah satunya yaitu limbah padat pengolahan Kayu Putih dan Gondorukem.

Tantangan dalam pengembangan biomassa sebagai bahan bakar diantaranya energi yang dihasilkan masih rendah jika dibakar secara langsung dan membutuhkan area penyimpanan yang besar sehingga berkaitan dengan permasalahan distribusi dan transportasi (Saptoadi, 2008). Permasalahan ini disebabkan oleh rendahnya bulk density (kerapatan) dari material biomassa. Biomasa dapat diolah menjadi biopelet untuk meningkatkan kualitasnya. Pengolahan biopelet akan meningkatkan bulk density biomassa sehingga dapat mengurangi area penyimpanan yang diperlukan dan memperbaiki kualitas pembakarannya (Liu et al, 2014). Penggunaan biopelet telah banyak berkembang seperti di Jerman dan Austria sebagai alternatif bahan bakar (Mani et al, 2006).

Biopelet merupakan salah satu bentuk bahan bakar padat yang terbuat dari biomassa dengan ukuran lebih kecil dari ukuran briket yang diproses menggunakan pengempaan pada suhu dan tekanan tinggi (Rusdianto et al, 2014). Pemanfaatannya diantaranya sebagai bahan bakar boiler, bahan bakar kompor masak, dan telah banyak digunakan sebagai subtitusi batu bara untuk bahan bakar penghangat ruangan pada perumahan (residential). Melihat tingginya kebutuhan biopelet dunia, Indonesia memiliki peluang yang sangat besar untuk turut serta memenuhi kebutuhan tersebut. Hal ini juga didukung oleh tingginya sumber biomassa yang dimiliki oleh Indonesia, seperti dari limbah pertanian yang mencapai 50.000 MW (Winata, 2013).

Pemanfaatan limbah padat pengolahan kayu putih sebagai bahan baku pembuatan biopelet diharapkan dapat dimanfaatkan sebagai energi alternatif bagi kebutuhan masyarakat dan ramah terhadap lingkungan. Dalam upaya meningkatkan kualitas biopellet, penambahan gondorukem diharapkan dapat meningkatkan sifat keteguhan dan kerapatan biopellet. Pemanfaatan limbah padat kayu putih oleh Perum Perhutani hanya sebesar 30\% untuk dijadikan briket sebagai bahan bakar boiler dan sisanya dijadikan kayu bakar oleh masyarakat. Namun itu tidak memberikan pengaruh signifikan dalam mengurangi tumpukan limbah yang setiap harinya terus bertambah (Kartikasari, 2007).

Berdasarkan uraian tersebut, tujuan penelitian ini adalah untuk menentukan komposisi campuran limbah padat kayu putih dan gondorukem sebagai biopelet serta menganalisis kualitas biopelet yang 
dihasilkan berdasarkan standar biopelet (SNI

\section{METODE PENELITIAN}

\section{Lokasi dan Waktu Penelitian}

Penelitian ini dilakukan di Laboratorium Kimia Terpadu, Litbang Kehutanan Bogor pada bulan Juni sampai Agustus 2016.

\section{Bahan dan Alat}

Bahan yang digunakan limbah padat pengolahan minyak kayu putih berupa

\section{Metode Pengumpulan Data}

Persiapan bahan baku yang dilakukan meliputi pengadaan bahan baku dan pembuatan serbuk. Limbah padat kayu putih dan gondorukem digiling menggunakan disc flaker, dan diperhalus lagi menggunakan willey mill untuk menghasilkan serbuk. Serbuk yang diperoleh dari hasil penggilingan kemudian diayak menggunakan saringan dengan ukuran yang diinginkan yaitu serbuk dengan ukuran 20 mesh. Serbuk yang diperoleh kemudian ditimbang dengan menggunakan perbandingan antara kayu putih dengan gondorukem masing-masing sebagai berikut (95\% : 5\%, 90\% : $10 \%, 80 \%: 20 \%, 70 \%$ : $30 \%, 60 \%: 40 \%, 50 \%: 50 \%$ ) dari $30 \mathrm{~g}$. Pencetakan biopelet dilakukan dengan menggunakan mesin kempa hidrolik bertekanan $526,48 \quad \mathrm{~kg} / \mathrm{cm}^{2}$ dengan menggunakan suhu pencetakan sebesar $200^{\circ} \mathrm{C}$ selama 15 menit. Adapun pengujian yang dilakukan adalah sebagai berikut.
8021-2014) Indonesia (SNI, 2014).

ranting, dan limbah padat gondorukem berupa serpihan yang mengkilat tercampur serasah daun pinus yang diambil dari Perum Perhutani Unit III Jawa Barat. Alat yang digunakan dalam penelitian ini adalah willey mill, disc flaker, saringan tyler, pellet mill, timbangan analitik, desikator, tanur, cawan porselen, stopwatch, kamera, kertas label, kuas, plastik, dan alat tulis.

1. Kerapatan (SNI 8021-2014)

Penetapan kerapatan dinyatakan dalam hasil perbandingan antara berat dan volume pellet yang diukur pada kondisi yang sama. Kerapatan sampel dihitung dengan menggunakan rumus :

Kerapatan $=\frac{\mathrm{B}}{\mathrm{V}}$

Keterangan

B : Berat contoh uji $(\mathrm{g})$

$\mathrm{V}$ : Volume contoh uji $\left(\mathrm{m}^{3}\right)$

2. Kadar air (SNI 8021-2014)

Penetapan nilai kadar air dilakukan dengan 2 g sampel diletakkan pada cawan porselen yang bobotnya sudah diketahui. Kemudian dimasukkan ke dalam oven pada suhu $103 \pm$ $2{ }^{\circ} \mathrm{C}$ selama 3 jam sampai kadar air konstan. Kemudian didinginkan dalam desikator sampai kondisi stabil dan seimbang. Perhitungan kadar air dapat dilakukan dengan rumus:

Kadar Air $\quad(\%) \quad=\frac{B B-B K T}{B K T} \quad \mathrm{X}$
$100 \%$ 
Keterangan: $\mathrm{BB}=$ Berat sebelum

dikeringkan dalam oven $(\mathrm{g})$.

$\mathrm{BKT}=$ Berat setelah dikeringkan dalam oven $(\mathrm{g})$.

3. Kadar Abu (SNI 8021-2014)

Penetapan nilai kadar abu dilakukan dengan

1 g sampel diletakkan pada cawan poselen yang bobotnya sudah diketahui. Kemudian dimasukkan ke dalam oven pada suhu $650^{\circ} \mathrm{C}$ selama 5 jam. Kemudian didinginkan dalam desikator sampai kondisi stabil dan seimbang. Perhitungan nilai kadar abu dapat dilakukan dengan menggunakan rumus:

Kadar Abu $(\%)=\frac{\text { Berat Abu }}{\text { Berat sampel kering tanur }} \mathrm{x}$ $100 \%$

4. Kadar Zat Terbang (SNI 8021-2014)

Penetapan nilai zat terbang dilakukan dengan 2 g sampel diletakkan pada cawan porselen yang bobotnya sudah diketahui. Kemudian dimasukkan ke dalam oven pada suhu $950^{\circ} \mathrm{C}$ selama 10 menit. Kemudian didinginkan dalam desikator sampai kondisi stabil dan seimbang. Perhitungan nilai kadar zat terbang dapat dilakukan dengan menggunakan rumus:

Kadar Zat Terbang $(\%)=$

$$
\frac{\mathrm{B}-\mathrm{C}}{\mathrm{W}} \times 100 \%
$$

Keterangan:

$\mathrm{B}=$ Berat sampel setelah dikeringkan dari uji

kadar air (g)

$\mathrm{C}=$ Berat sampel setelah dipanaskan dalam tanur $(\mathrm{g})$

$\mathrm{W}=$ Berat sampel awal sebelum pengujian

kadar air (g)
5. Kadar Karbon Terikat (SNI 8021-2014)

Kadar karbon terikat merupakan kadar fraksi karbon yang terikat dalam bahan dan tidak termasuk fraksi air, zat mudah menguap dan abu. Perhitungan nilai kadar karbon terikat dapat dilakukan dengan menggunakan rumus:

Kadar Karbon Terikat (\%) = $100-$ (Kadar air + kadar zat terbang + kadar abu) .. (4)

6. Nilai Kalor (SNI 8021-2014)

Nilai kalor adalah jumlah panas yang dihasilkan oleh pembakaran lengkap dari sebuah jumlah unit bakar. Penetapan nilai kalor dapat dilakukan dengan contoh uji sebanyak $2 \mathrm{~g}$ diletakkan dalam cawan silika dan diikat dengan kawat nikel kemudian dimasukkan ke dalam tabung dan ditutup rapat. Pada tabung tersebut dialiri oksigen selama 30 detik dan tabung akan dimasukkan ke dalam Oxygen Bomb Calorimeter. Pembakaran akan dimulai saat suhu air sudah tetap. Pengujian nilai kalor ini dilakukan di Laboratorium Balai Penelitian Ternak, Ciawi. Besarnya nilai kalor suatu bahan dapat dihitung dengan menggunakan persamaan sebagai berikut:

Nilai Kalor $(\mathrm{kkal} / \mathrm{kg}) \quad=$

$$
\frac{\Delta \mathrm{txW}}{\mathrm{mbb}}-\mathrm{B}
$$

Keterangan:

$\Delta \mathrm{t} \quad=$ Perbedaan suhu rata-rata $\left({ }^{\circ} \mathrm{C}\right)$

$\mathrm{W}=$ Nilai air kalorimeter $\left(\mathrm{kal} /{ }^{\circ} \mathrm{C}\right)$

$\mathrm{Mbb}=$ Massa bahan bakar $(\mathrm{g})$ 
B = Koreksi panas pada kawat besi

\section{Rancangan Penelitan}

Rancangan yang digunakan dalam penelitian ini adalah Rancangan Acak Lengkap, dimana terdiri dari 6 taraf, yaitu perbandingan komposisi (95:5, 90:10, 80:20,

\section{HASIL DAN PEMBAHASAN}

Dari hasil pengujian terhadap karakteristik biopelet terkait kerapatan, kadar air, kadar abu, kadar zat terbang, $(\mathrm{kal} / \mathrm{g})$

$70: 30, \quad 60: 40, \quad 50: 50), \quad$ dan dilakukan pengulangan sebanyak 2 kali. Adapun terjadinya pengaruh nyata akan dilakukan pengujian lanjut. pada Tabel 1.

Tabel 1. Hasil Pengujian Karakteristik Biopelet.

\begin{tabular}{ccccccc}
\hline Perlakuan & \multicolumn{5}{c}{ Pengujian Karakteristik Biopelet } \\
\cline { 2 - 6 } & $\begin{array}{c}\text { Kerapatan } \\
\left(\mathrm{g} / \mathrm{cm}^{3}\right)\end{array}$ & $\begin{array}{c}\text { Kadar air } \\
(\%)\end{array}$ & $\begin{array}{c}\text { Kadar abu } \\
(\%)\end{array}$ & $\begin{array}{c}\text { Zat Terbang } \\
(\%)\end{array}$ & $\begin{array}{c}\text { Karbon terikat } \\
(\%)\end{array}$ & $\begin{array}{c}\text { Nilai kalor } \\
(\mathrm{kkal} / \mathrm{kg})\end{array}$ \\
\hline KP 100\% & 0,77 & 5,89 & 3,89 & 68,02 & 22,84 & 4714 \\
KP 95 \% + G 5\% & 0,79 & 5,96 & 4,32 & 71,02 & 20,13 & 4749 \\
KP 90\% + G 10\% & 0,80 & 5,37 & 2,79 & 72,69 & 20,09 & 4755 \\
KP 80 \% + G 20\% & 0,82 & 6,85 & 3,55 & 70,01 & 21,69 & 4966,5 \\
KP 70\% + G 30\% & 0,84 & 5,89 & 2,42 & 73,99 & 18,96 & 5152 \\
KP 60\% + G 40\% & 0,87 & 6,66 & 5,05 & 71,28 & 18,58 & 5141,5 \\
KP 50\% + G 50\% & 0,89 & 6,80 & 5,38 & 74,75 & 15,09 & 5288 \\
G 100\% & 0,99 & 4,87 & 7,09 & 73,32 & 15,88 & 5822,5 \\
\hline
\end{tabular}

Ket: $\mathrm{KP}=$ Kayu Putih, $\mathrm{G}=$ Gondorukemm Sumber: data primer.

\section{Kerapatan}

Kerapatan merupakan salah satu sifat mekanis biopellet yang merupakan perbandingan antara massa dan volume (SNI 2014). Nilai kerapatan merupakan parameter yang digunakan untuk mengetahui kualitas biopelet. Semakin tinggi nilai kerapatan biopelet dapat memudahkan dalam hal penanganan, penyimpanan dan transportasi biopelet, sehingga dapat menurunkan biaya yang dibutuhkan (Adapa et al, 2009). Nilai kerapatan pada penelitian ini berkisar antara $0,77-0,99 \mathrm{~g} / \mathrm{cm}^{3}$. Dari hasil penelitian ini nilai kerapatan tertinggi terdapat pada Gondorukem $100 \%$ yaitu sebesar $0,99 \mathrm{~g} / \mathrm{cm}^{3}$ dan terendah terdapat pada Kayu putih $100 \%$ yang memiliki nilai kerapatan sebesar $0,77 \mathrm{~g} / \mathrm{cm}^{3}$. Hal ini menunjukkan bahwa dengan adanya penambahan Gondorukem dapat meningkatkan kerapatan. Besarnya kerapatan biopelet dapat disebabkan oleh kandungan lignin pada gondorukem. Lignin 
bersifat termoplastik sehingga dapat digunakan sebagai perekat yang dapat meningkatkan kerapatan biopelet (Saragih, 2013)

Kerapatan biopelet menurut SNI yang mensyaratkan bahwa nilai kerapatan biopelet yang baik adalah diatas $0,8 \mathrm{~g} / \mathrm{cm}^{3}$. Hasil penelitian ini menunujukkan bahwa pengaruh penambahan Gondorukem memberikan pengaruh terhadap nilai kerapatan biopelet pada taraf $\alpha$ sebesar 5\%. Uji duncan menunjukkan bahwa Gondorukem 100\% memberikan pengaruh nyata terhadap Kayu Putih $100 \%$. Nilai kerapatan biopellet ini berkaitan dengan penanganan, semakin tinggi kerapatannya maka semakin mempermudah proses pengepakan, transportasi dan penyimpanan (Adapa et al, 2009). Kerapatan biopelet yang terlalu tinggi akan mengakibatkan biopelet sulit terbakar, namun dapat meningkatkan nilai kalor dan keteguhan tekannya (Hendra, 2012). Semakin kecil ukuran partikel maka kerapatan biopellet yang dihasilkan relatif lebih besar (Saptoadi, 2008).

\section{Kadar Air}

Kadar air adalah rasio kandungan air dalam bahan yang hilang selama proses pengeringan dibanding berat awal (Saptoadi, 2008). Penetapan kadar air bertujuan untuk mengetahui sifat higroskopis biopelet yang dihasilkan (Hendra,2012). Tinggi dan rendahnya nilai kadar air mempengaruhi nilai kalor. Semakin rendah nilai kadar air maka akan meningkatkan nilai kalor. Rendahnya nilai kadar air akan memudahkan proses dalam penyalaan dan menurunkan jumlah asap saat pembakaran. Nilai kadar air dipengaruhi oleh tekanan yang diberikan saat pencetakan biopelet. Tinggi tekanan saat pencetakan biopelet menyebabkan biopelet semakin padat, kerapatan tinggi, halus dan seragam, sehingga partikel biomassa dapat saling mengisi pori - pori yang kosong serta menurunkan molekul air yang dapat menempati pori - pori tersebut (Rahman, 2011).

Nilai kadar air biopelet penelitian ini diperoleh nilai antara 4,87-6,85\%. Menurut Sutada dan Hidayat (2011) kadar air biopelet berdasarkan penelitian untuk bahan baku limbah daun dan ranting penyulingan minyak Kayu Putih yaitu berkisar 6,59,72\%, sedangkan pada hasil penelitian ini kadar air untuk bahan baku Kayu Putih adalah sebesar $8,07 \%$ dan untuk Gondorukem adalah sebesar 7,18\%. Kadar air terendah terdapat pada perlakuan Gondorukem $100 \%$ yaitu sebesar $4,87 \%$ dan tertinggi terdapat pada campuran Kayu Putih $80 \%+$ Gondorukem 20\% yaitu sebesar $6,85 \%$.

Dengan adanya penambahan Gondorukem dapat meningkatkan terjadinya penurunan kadar air. Hal ini disebabkan oleh rendahnya komponen kadar air gondorukem dibandingkan dengan Kayu putih. 
Berdasarkan hasil uji analisis sidik ragam untuk menetukan kadar air tiap perlakuan

\section{Kadar Abu}

Abu merupakan bagian yang tersisa dari proses pembakaran yang sudah tidak memiliki unsur karbon. Unsur utama abu adalah silika dan pengaruhnya kurang baik terhadap nilai kalor bakar yang dapat menurunkan kualitas pelet karena unsur silika tidak terbakar pada waktu pembakaran (Hendra, 2012). Kadar abu biopelet berkisar antara 2,42-7,09\%. Kadar abu tertinggi terdapat pada Gondorukem $100 \%$ yaitu sebesar 7,09\% dan terendah terdapat pada campuran Kayu putih $70 \%$ dengan Gondorukem 30\% yaitu sebesar 2,42\%.

Kadar abu yang tinggi pada biopelet disebabkan oleh tingginya komponen abu pada gondorukem yaitu sebesar 9,63\%. Semakin besar campuran gondorukem maka semakin besar pula nilai kadar abu pada biopelet. Hasil analisis sidik ragam menunjukkan bahwa adanya pengaruh nyata perlakuan gondorukem murni terhadap perlakuan lainnya.

\section{Kadar Zat Terbang}

Zat terbang merupakan zat yang dapat menguap sebagai hasil dekomposisi senyawa-senyawa di dalam suatu bahan selain air (Hendra, 2012). Zat terbang biopelet adalah sekitar 68,02\%-74,75\%. Dengan adanya penambahan Gondorukem dapat meningkatkan nilai kadar zat terbang. Tingginya nilai kadar zat terbang ini salah tidak memberikan pengaruh yang nyata terhadap kadar air biopelet.

satu faktor yang mempengaruhinya yaitu tidak dilakukan karbonisasi pada serbuk kayu yang digunakan. Hal tersebut dibuktikan oleh Liliana (2010) yang menyatakan bahwa karbonisasi sekam padi bertujuan untuk mengurangi kadar zat terbang penyebab asap dan meningkatkan nilai kalor pembakaran. Selain ituuntuk bahan baku limbah daun dan ranting penyulingan minyak Kayu Putih yaitu berkisar 45.78-50.78\% (Sutapa dan Hidayat, 2011). Sementara pada penelitian ini nilai kadar zat terbang untuk bahan baku Kayu Putih sebesar $88,77 \%$ dan untuk Gondorukem sebesar 84,39\%. Nilai kadar zat terbang tersebut memenuhi SNI 80212014 yang mensyaratkan bahwa nilai kadar zat terbang maksimal $80 \%$.

Hasil analisis sidik ragam menunjukkan tidak adanya pengaruh nyata pada tiap perlakuan. Penggunaan pellet untuk bahan bakar rumah tangga, pellet harus memiliki kadar zat terbang yang rendah agar tidak menimbulkan polusi. Semakin tinggi kadar zat terbang suatu bahan bakar, maka efisiensi pembakaran bahan bakar akan menurun dan asap yang dihasilkan semakin banyak (Nurwigha 2012).

\section{Karbon Terikat}


Kadar karbon terikat didefinisikan sebagai fraksi karbon dalam biomassa selain fraksi air, zat terbang, dan abu. Besar kecilnya kadar karbon terikat dapat dipengaruhi oleh tinggi rendahnya kadar zat terbang (Pari, 2004). ]. Hasil menunjukan nilai karbon terikat berkisar 15,09\%$22,84 \%$. Karbon terikat tertinggi pada perlakuan Kayu putih 100\% yaitu sebesar 22,84 dan terendah terdapat pada perlakuan Kayu putih $60 \%$ dengan Gondorukem $40 \%$ yaitu sebesar $15,09 \%$.

Hasil analisis sidik ragam menunjukkan adanya pengaruh nyata pada perlakuan Kayu Putih $100 \%$ dengan perlakuan lainnya, kecuali perlakuan campuran Kayu putih $80 \%$ dengan Gondorukem 20\%. Kadar karbon terikat berbanding terbalik dengan zat terbang. (Hendra dan Darmawan, 2002) menyatakan semakin besar kadar zat terbang, maka akan menurunkan kadar karbon terikat. Biopelet dengan komposisi pelepah murni mempunyai kadar zat terbang yang tinggi, sehingga kadar karbon terikatnya akan rendah. Selain itu, tinggi atau rendahnya kadar karbon terikat berpengaruh terhadap nilai kalor. Menurut Onu et al (2010) semakin tinggi kadar karbon terikat, maka nilai kalor akan semakin tinggi.

\section{Nilai Kalor}

Nilai kalor merupakan parameter utama kualitas biopelet, dan sangat penting dalam menentukan efisiensi suatu bahan bakar (Ali dan Restuhadi, 2010). Menurut Basu (2010) nilai kalor dipengaruhi oleh kadar air, kadar zat terbang, kadar abu dan kadar karbon terikat. Nilai kalor pada penelitian ini berkisar antara 4714-5822,5 $\mathrm{kkal} / \mathrm{kg}$. Nilai kalor tertinggi dihasilkan pada perlakuan Gondorukem 100\% dan terendah pada perlakuan Kayu Putih 100\%.

Hasil analisis sidik ragam menunjukkan adanya pengaruh yang sangat nyata dari tiap perlakuan. Nilai kalor biopelet juga dipengaruhi oleh nilai kalor bahan baku biopelet. Hal ini sesuai dengan Rusdianto (2013) yang menyatakan semakin tinggi nilai kalor bahan bakunya akan berakibat semakin tinggi nilai kalor biopelet yang dihasilkan. Semakin tinggi suhu maka semakin tinggi nilai kalor biopelet yang dihasilkan. Hal ini disebabkan karena tingginya nilai kalor godorukem yang digunakan sebagai bahan baku pembuatan biopelet. Nilai kalor bahan baku limbah gondorukem pada penelitian ini diperoleh dari hasil pengujian bahan baku pada penelitian pendahuluan yaitu sebesar 5212 $\mathrm{kkal} / \mathrm{kg}$.

\section{KESIMPULAN DAN SARAN}

\section{Kesimpulan}

Limbah padat Kayu Putih dan Gondorukem dapat dimanfaatkan menjadi sumber energi alternatif berupa biopelet. Komposisi yang terbaik pada penelitian ini adalah campuran Kayu Putih 70\% dengan Gondorukem 30\% dengan hasil pengujian 
karakteristik biopelet sesuai SNI 8021-2014 diperoleh nilai kerapatan sebesar $0,84 \mathrm{~g} / \mathrm{cm}^{3}$, kadar air sebesar 5,89\%, kadar abu sebesar $2,42 \%$, nilai zat terbang sebesar 73,99\%, nilai karbon terikat sebesar $18,96 \%$, dan nilai kalor sebesar $5152 \mathrm{kkal} / \mathrm{kg}$.

\section{DAFTAR PUSTAKA}

Adapa P, Tabil L, Schoenau G. 2009. Compression Characteristics of Selected Ground Agricultural Biomass. Agricultural Engineering International: the CIGR Ejournal 9: 1347.

Ali, A., \& Restuhadi, F. (2010). Optimasi pembuatan biopelet dari bungkil Picung (pangium edule Reinw) dengan penambahan solar dan perekat tapioka. Sagu, 9(1), 1-7.

Basu, P. (2010). Biomass gasification and pyrolisis, practical design and theory. (US): Academic Press.

Bergman, R., \& Zerbe, J. (2008). Primer on Wood Biomass for Energy, 1-10. Retrieved from

http://www.fpl.fs.fed.us/documnts/fpmu/b iomass_energy/primer_on_wood_biomas s_for_energy.pdf

Christanty NA. 2014. Biopelet Cangkang dan Tandan Kosong Kelapa Sawit sebagai Sumber Energi Alternatif Terbarukan [skripsi]. Bogor (ID): Institut Pertanian Bogor.

Hendra, D., \& Darmawan, S. (2002). Pembuatan briket arang dari serbuk gergajian dengan penambahan tempurung kelapa. Buletin Penleitian Hasil Hutan, 18, 1-9.

Hendra D. 2012. Rekayasa pembuatan mesin pellet kayu dan pengujian hasilnya. $J$ Penelitian Hasil Hutan. 30(2):144-154.

\section{Saran}

Perlu dilakukan penelitian lanjutan dengan perbedaan suhu pengempaan, dan perlu dilakukan pengujian konsumsi dan efisiensi pembakaran biopelet. Selain itu, pembuatan biopelet diharapkan dapat memanfaatkan bahan baku limbah biomassa yang lain.

Kartikasari, D. (2007). Studi pengusahaan minyak kayu putih (cajeput oil) di PMKP Jatimunggul, KPH Indramayu Perum Perhutani Unit III Jawa Barat dan Banten [skripsi]. Bogor (ID): Institut Pertanian Bogor.

Liliana, W. (2010). Peningkatan kualitas biopelet bungkil jarak pagar sebagai bahan bakar melalui teknik karbonisasi. [Tesis]. Bogor (ID): Program Pascasarjana Institut Pertanian Bogor.

Liu, Z., Fei, B., Jiang, Z., Cai, Z., \& Liu, $X$. (2014). Important Properties of Bamboo Pellets to Be Used as Commercial Solid Fuel in China. Journal Wood Science and Technology, 48(5), 903-917.

Mani S, Tabil LG, Sokhansanj S. 2006. Effects of Compressive Force, Particle Size and Moisture Content on Mechanical Properties of Biomass Pellets from Grasses. Biomass and Bioenergy (30): $648-654$.

Nurwigha, R. (2012). Pembuatan biopelet dari cangkang kelapa sawit dengan penambahan arang cangkang sawit dan serabut sawit sebagai bahan bakar alternatif terbarukan. (Skripsi). Bogor (ID): Institut Pertanian Bogor.

Onu, F., Rahman, M.B.N., \& Sudarja. (2010). Pengukuran nilai kalor bahan bakar briket arang kombinasi cangkang pala (myristica fragan Houtt) dan limbah sawit (elaeis guinennsis). Seminar 
Nasional Teknik Mesin. UMY; Yogyakarta, Indonesia.

Pari, G. (2004). Kajian struktur arang aktif dari serbuk gergaji kayu sebagai adsorben emisi formaldehida kayu lapis [Disertasi Doktor]. Bogor (ID): Institut Pertanian Bogor.

Rahman. 2011. Uji keragaan biopelet dari biomassa limbah sekam padi (Oryza sativa sp.) sebagai bahan bakar alternatif terbarukan [skipsi]. Bogor (ID): Institut Pertanian Bogor.

Rusdianto, A.S. (2013). Kajian potensi penggunaan $B y$ product industri pertanian di kabupaten jember sebagai bahan baku pembuatan biopelet untuk bahan bakar alternatif. Fakultas Teknologi Pertanian, Universitas Jember. Jember.

Rusdianto, A.S., Choiron, M., \& Novijanto N. (2014). Karakterisasi limbah industri tapee sebagai bahan baku pembuatan biopelet. Jurnal Industrialisasi, 1(3), 2732.

Saptoadi H. 2008. The best briquette dimension and its particle size. Asian J. Energy Environ. 9:161-175.
Saragih AE. 2013. Karakteristik biopelet dari campuran cangkang sawit dan kayu sengon sebagai bahan bakar alternatif terbarukan [skripsi]. Bogor (ID): Institut Pertanian Bogor.

[SNI] Standar Nasional Indonesia. (2014). Pelet kayu. (SNI 8021-2014). Badan Standardisasi Nasional. Jakarta

Sutapa JPG, Hidayat AN. 2011. Pemanfaatan Limbah dan Daun Ranting Penyulingan Minyak Kayu Putih (Melaleuca cajuputi Powell) untuk Membuat Arang Aktif. Prosiding Seminar Nasional Masyarakat Peneliti Kayu Indonesia (MAPEKI) XIV; 2011. Nov 2; 379-385 Yogyakarta, Indonesia. Yogyakarta (ID): MAPEKI. hlm 379-385.

Winata, A. (2013). Karakteristik Biopelet dari Campuran Serbuk Kayu Sengon dengan Arang Sekam Padi sebagai Bahan Bakar Alternatif Terbarukan (Skripsi). Institut Pertanian Bogor, Bogor, Indonesia. 